\title{
Bilateral intraorbital abscesses with intracranial complications in a young Cameroonian girl: a case report
}

This article was published in the following Dove Press journal:

Clinical Ophthalmology

3 September 2012

Number of times this article has been viewed

\section{Oumarou Abdouramani ${ }^{1}$ \\ S Nguefack ${ }^{2,3}$ \\ VA Dohvoma ${ }^{3}$ \\ B Moifo 3,5 \\ André Omgbwa Eballé \\ A Moho ${ }^{4}$ \\ E Epee $^{3}$ \\ E Mbonda ${ }^{2,3}$ \\ AL Bella ${ }^{3}$ \\ 'Ophthalmology Unit, Yaoundé Gynaeco-obstetric and Paediatric Hospital (YGOPH), ${ }^{2}$ Neuropaediatric Unit, YGOPH, ${ }^{3}$ Faculty of Medicine and Biomedical Sciences, University of Yaoundé I, ${ }^{4}$ Ear, Nose, and Throat Unit, YGOPH, ${ }^{5}$ Radiology Unit, YGOPH, Cameroon}

Correspondence: Oumarou Abdouramani Yaoundé Gynaeco-obstetric and Paediatric Hospital, BP 4362 Yaoundé, Cameroon Tel +2379959 I4 83

Emailabdou_dr@yahoo.fr
Background: Intraorbital abscess is a very severe infection with ophthalmologic and neurologic complications that are sometimes life-threatening.

Objective: To report the etiologic, clinical, radiologic, and prognostic features of one case of bilateral intraorbital abscesses with intracranial complications.

Case report: A 15-year-old Cameroonian girl in a comatose state (11/15 on the Glasgow Coma Scale) with meningeal signs, right hemiplegia, right facial palsy, and bilateral exophthalmia was admitted for meningitis and cerebral abscess secondary to orbital cellulitis. A lumbar tap was carried out, no organisms were seen by Gram stain, and culture was negative due to previous antibiotic therapy. A computed tomography scan showed a left internal capsule infarct and a pansinus opacification. Bilateral superior orbitotomies were performed and the abscess evacuated. Microscopy and culture of surgical material were negative. The patient was discharged 4 weeks after hospital admission with a visual acuity of 0.1 in both eyes, aphasia, and right hemiplegia. Nine months later, there was complete visual recovery (visual acuity 1.0 in both eyes). Anterior and posterior segments were normal on slit-lamp examination. There was no aphasia, but rightsided hemiparesis persisted.

Conclusion: The authors emphasize the need for prevention, early diagnosis, and adequate treatment of orbital cellulitis in order to avoid complications.

Keywords: intraorbital abscess, orbital cellulitis, orbitotomies, hemiparesis, intracranial complications, pansinusitis

\section{Introduction}

Orbital cellulitis is an acute infectious inflammation of the orbit. It could be preseptal or retroseptal. Infants mostly present with preseptal cellulitis, whereas retroseptal cellulitis mostly occurs in older children. ${ }^{1}$ Retroseptal cellulitis could be diffuse or focal, with collection of pus in the orbital cavity. Paranasal sinusitis is the most common source of infection. ${ }^{1,2}$

Risk factors commonly described include impairment of local nasal immunity, congenital immune deficiency such as hypogammaglobulinemia, and acquired states of immune suppression such as chemotherapy and cancer.

The diagnosis of orbital cellulitis is made clinically, and imaging is required for confirmation and delineating the source and extension of the infection. Medical treatment with broad-spectrum antibiotics must be timely to prevent complications, which could be orbital or cerebral.

Intracranial complications are rare but potentially life-threatening. Long-term sequelae could also result. 
We report the case of a 15 -year-old girl with bilateral orbital abscesses who presented with two intracranial complications: meningitis and ischemic brain infarction.

\section{Case report}

A 15-year-old girl with an unremarkable medical history had complaints of headache and fever. She received oral paracetamol and indomethacine at home and there was transient relief. She became symptomatic again and a left eyelid edema developed. Medical attention was sought at a district hospital, where she received symptomatic treatment with oral betamethasone and loratadine. Her symptoms worsened, the eyelid edema became bilateral, and neck stiffness developed. She was admitted and started on ceftriaxone, gentamycin, dexamethasone, and mannitol intravenously. With deteriorating mental status, she was transferred to a Yaoundé referral hospital.

On admission to the pediatric unit 7 days after the onset of symptoms, she was comatose (11/15 on the Glasgow Coma Scale) with marked meningismus. Right hemiplegia, right facial palsy, bilateral exophthalmia, bilateral chemosis, bilateral eyelid edema (Figure 1), and exposure keratitis were present. A working diagnosis of severe meningitis or cerebral abscess secondary to orbital cellulitis was made. A lumbar tap was carried out and broad-spectrum intravenous antibiotic therapy was initiated with ceftriaxone, gentamycin, and metronidazole.

Cerebrospinal fluid analysis was remarkable for pleocytosis with 390 white blood cells $/ \mathrm{mm}^{3}$ ( $60 \%$ neutrophils and $40 \%$ lymphocytes), raised proteins $(2.27 \mathrm{~g} / \mathrm{L})$, and decreased glucose $(0.24 \mathrm{~g} / \mathrm{L})$. No organisms were seen by Gram stain, and culture was negative. Complete blood count revealed leukocytosis $\left(15,600 \mathrm{cells} / \mathrm{mm}^{3}\right)$ and a hemoglobin concentration of $11.8 \mathrm{~g} / \mathrm{dL}$. Erythrocyte sedimentation rate was $40 \mathrm{~mm}$ in the first hour. A computed tomography scan revealed bilateral exophthalmia with intraorbital abscesses and frontal and maxillary sinus opacifications (Figure 2).

Ophthalmic consultation was sought 4 days later. It revealed fistulization to the left upper eyelid. Needle aspiration

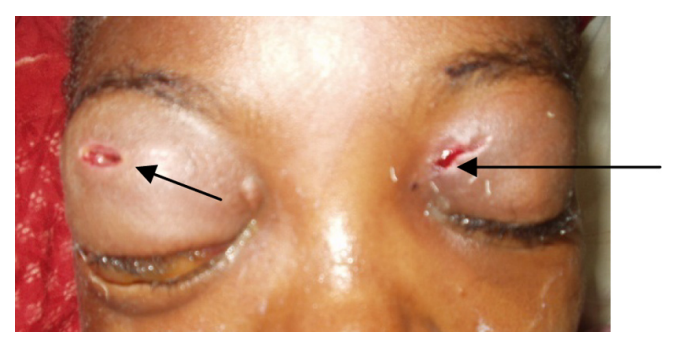

Figure I Photograph of patient following orbitotomies. Note bilateral exophthalmia, bilateral chemosis and bilateral eyelid oedema. The two arrows are pointing at the two orbitotomies.
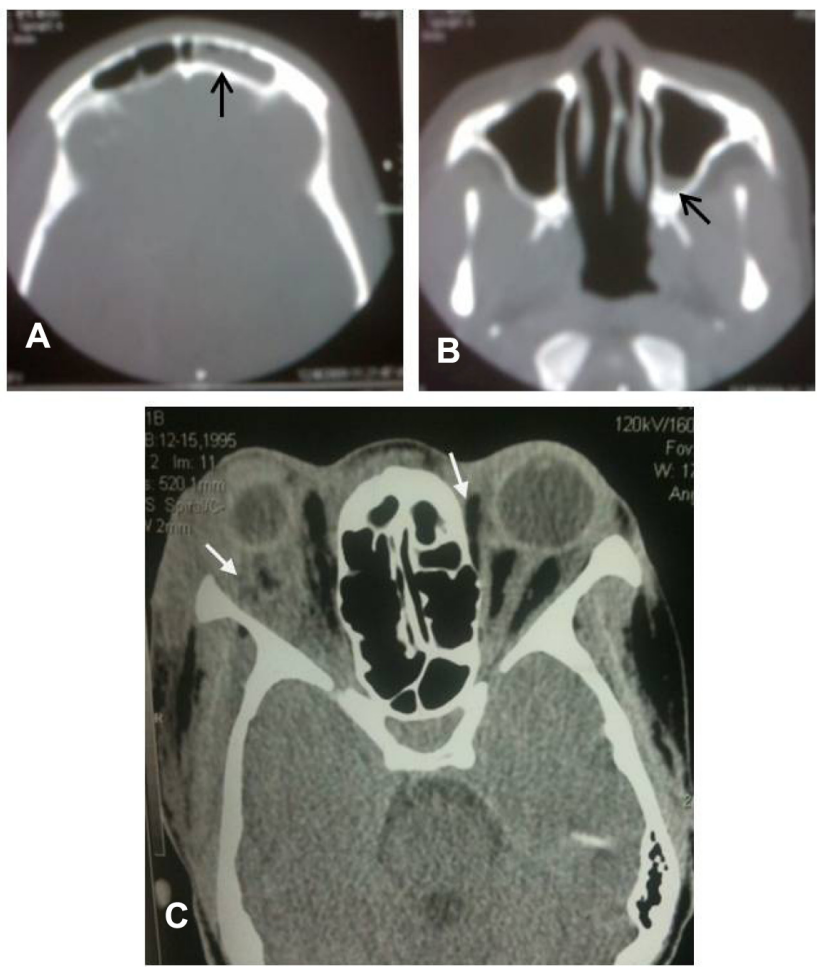

Figure 2 (A) Frontal sinusitis, (B) maxillary sinusitis, and (C) bilateral intraorbital abscesses.

of the right orbit yielded $2 \mathrm{~mL}$ of purulent material. Bilateral superior orbitotomies were performed and the abscess evacuated. Microscopy of surgical material revealed acute inflammatory cells mixed with a few clusters of Gram-positive cocci. Culture was negative. Topical fucidic acid was given and dressings applied daily. Artificial tear drops were also given for corneal exposure.

A total of $1000 \mathrm{~mL}$ of whole blood was transfused because of severe anemia on Day 8. She later developed cough and fine crackles on both lung fields. Chest X-ray showed bilateral pneumonia. Because of pneumonia and persistent fever, antibiotic therapy was changed to chloramphenicol and amikacine. A repeat computed tomography scan showed a left internal capsule infarct (Figure 3).

Amikacine and chloramphenicol were used for 8 days and 14 days, respectively. Exophthalmia slowly resolved and her temperature dropped. The patient was discharged 4 weeks after hospital admission with a visual acuity of 0.1 in both eyes, aphasia, and right hemiplegia. Oral azithromycine, iron sulfate, and 5\% carbocysteine, as well as rehabilitation, were continued on an outpatient basis. Nine months later, there was complete visual recovery, and anterior and posterior segments were normal on slit-lamp examination. There was no aphasia, but right-sided hemiparesis persisted. 


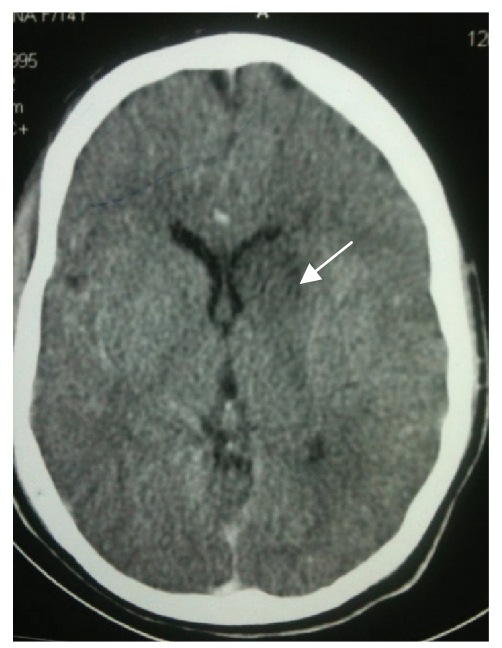

Figure 3 Left internal capsule infarct.

\section{Discussion}

Preseptal cellulitis represents Group I of Chandler's classification of orbital infection, and retroseptal cellulitis represents Groups II-V. ${ }^{3}$ Cavernous sinus thrombosis (Group V) is classified by others as an intracranial complication. ${ }^{4}$ Retroseptal cellulitis occurs in about one-third of patients with orbital infections. ${ }^{1}$

Intraorbital abscess (Group IV) in the setting of sinus disease is usually associated with late diagnosis or treatment. ${ }^{5}$ It occurs either from the collection of existing inflammation of the orbit (Group II) or direct extension of a subperiosteal abscess (Group III). Intraorbital abscesses are rare. They occur in $1 \%$ of orbital and periorbital complications of sinusitis. ${ }^{6}$ Bilateral intraorbital abscesses are extremely rare, and cases reported are usually associated with virulent pathogens and more serious complications.,

Intracranial complications are rare. Oxford and McClay ${ }^{8}$ reported 14 cases in a series of 104 children (13.5\%) with acute sinusitis. Intracranial complications are potentially life-threatening and occur mostly in older children. ${ }^{9}$ The mean age for retroseptal cellulitis is higher than that for preseptal cellulitis. Ailal et al, ${ }^{1}$ in a series of 33 patients with orbital infections, reported mean ages of 9 years and 4 years for retroseptal and preseptal cellulitis, respectively. Oxford and $\mathrm{McClay}^{8}$ reported a mean age of 12.3 years. Intracranial complications are usually associated with frontal sinusitis, ${ }^{4}$ as the frontal sinuses develop during childhood. Our patient was aged 15 years and presented with frontal sinusitis as well as ethmoidal and sphenoidal sinusitis, which increase the risk for intracranial complications. Viral upper respiratory tract infection is a common predisposing factor for the development of acute sinusitis in children. ${ }^{10}$
Intracranial complications include epidural empyema, subdural empyema, intracranial abscess, meningitis, cavernous sinus thrombosis, ischemic brain infarction, and Pott's puffy tumor. Pott's puffy tumor is a localized swelling of the forehead secondary to a subperiosteal bone abscess, occurring most commonly as a complication of frontal sinusitis. ${ }^{8}$ Epidural and subdural empyemas are the two most common intracranial complications. ${ }^{8}{ }^{811}$ Meningitis could be purulent ${ }^{1}$ or secondary to vasculitis. ${ }^{5}$ Our patient had meningitis and ischemic brain infarction. The cerebrospinal fluid analysis was indicative of purulent meningitis. No pathogen was identified, however, probably because of the use of antibiotic therapy prior to presentation. Surgical cultures were also negative in our patient. Ailal et al ${ }^{1}$ were able to identify the pathogen in $30.3 \%$ of cases $(70 \%$ blood cultures and 30\% surgical cultures). Oxford and McClay, ${ }^{8}$ however, reported a positive blood culture in $5.97 \%$ and positive surgical culture in $94.44 \% .{ }^{8}$ Mortimore et a ${ }^{12}$ reported a negative culture rate of $20 \%$ from sinus washouts and orbital and intracranial surgical materials. Inability to culture organisms is attributed to preceding antibiotic therapy. ${ }^{1,9}$ The most common pathogen in cases with intracranial complications is Streptococcus milleri. ${ }^{7,8,11}$ Stapylococcus aureus has been reported as a common pathogen. ${ }^{1}$ Age has been shown to influence bacteriology. Patients younger than 9 years usually have a single aerobic organism, whereas older ones have polymicrobial (mixed aerobic and anaerobic) organisms. ${ }^{13}$

Initial empiric antibiotic therapy requires broad-spectrum antibiotics that cover these organisms. Our patient received ceftriaxone, gentamycin, and metronidazole, which are broad spectrum for aerobic and anaerobic organisms, as first-line empiric antibiotic therapy. Ceftriaxone and metronidazole have been used by some authors. ${ }^{5,7}$ Associated aminoside use has been reported. ${ }^{1}$ With persistent fever and the onset of pneumonia in our patient, antibiotics were changed to chloramphenicol and amikacine. The pneumonia probably resulted from a blood-borne spread of infection. Anemia was probably the result of severe infection.

Surgical drainage of abscess is indicated as soon as possible. Late drainage was responsible for fistulization to the eyelid. Fistulization to the eyelid requires immediate drainage. ${ }^{14}$ Early drainage prevents ischemic optic neuropathy, which could be primary (toxic neuritis from adjacent purulent inflammation) or secondary to ischemic vascular compression to the central retinal artery or to nutrient vessels. ${ }^{15}$

Long-term sequelae such as ophthalmoplegia, blindness, aphasia, motor deficits, ${ }^{1}$ hearing loss, ${ }^{5}$ and cranial nerve 
palsies ${ }^{7}$ have been reported. Kabre et $\mathrm{al}^{14}$ reported no sequelae in two cases with intracranial abscesses. Our patient responded well to antibiotics and surgical drainage. She recovered her vision and speech. Right hemiparesis was the only long-term sequel. Temporary aphasia was probably due to ischemia in the foot of the third frontal gyrus (F3) of the left hemisphere, which was dominant in this patient, especially as this was associated with right central facial palsy. Residual hemiparesis could be explained by infarction in the left internal capsule (Figure 3).

\section{Conclusion}

Orbital cellulitis is a severe disease that could result in functional and esthetic sequelae. Prompt diagnosis and management may prevent this. The use of broad-spectrum antibiotics in early management will reduce the risk of complications. A multidisciplinary team approach in management and monitoring is necessary, given potential ophthalmic and neurologic complications. We found no risk factor for complications in this patient. Our patient had a favorable recovery, with right hemiparesis being the only long-term sequela.

\section{Disclosure}

The authors report no conflicts of interest in this work.

\section{References}

1. Ailal F, Bousfiha A, Jouhadi Z, Bennani M, Abid A. Orbital cellulitis in children: a retrospective study of 33. Med Trop (Mars). 2004;64(4): 359-362. French.
2. Suneetha N, Battu RR, Thomas RK, BoscoA. Orbital abscess: management and outcome. Indian J Ophthalmol. 2000;48(2):129-134.

3. Chandler JR, Langenbrunner DJ, Stevens ER. The pathogenesis of orbital complications in acute sinusitis. Laryngoscope. 1970;80(9): 1414-1428.

4. Mortimore S, Wormald PJ. The Groote Schuur Hospital classification of the orbital complications of sinusitis. J Laryngol Otol. 1997;111(8): 719-723.

5. Watkins LM, Pasternack MS, Banks M, Kousoubris P, Rubin PA. Bilateral cavernous sinus thromboses and intraorbital abscesses secondary to Streptococcus milleri. Ophthalmology. 2003;110(3):569-574.

6. Patt BS, Manning SC. Blindness resulting from orbital complications of sinusitis. Otolaryngol Head Neck Surg. 1991;104(6):789-795.

7. Udaondo P, Garcia-Delpech S, Diaz-Llopis M, Salom D, Garcia-Pous M, Strottmann JM. Bilateral intraorbital abscesses and cavernous sinus thromboses secondary to Streptococcus milleri with a favorable outcome. Ophthal Plast Reconstr Surg. 2008;24(5):408-410.

8. Oxford LE, McClay J. Complications of acute sinusitis in children. Otolaryngol Head Neck Surg. 2005;133(1):32-37.

9. Zimmerman RA, Bilaniuk LT. CT of orbital infection and its cerebral complications. AJR Am J Roentgenol. 1980;134(1):45-50.

10. Fireman P. Diagnosis of sinusitis in children: emphasis on the history and physical examination. J Allergy Clin Immunol. 1992;90(3 Pt 2): 433-436.

11. Jones NS, Walker JL, Bassi S, Jones T, Punt J. The intracranial complications of rhinosinusitis: can they be prevented? Laryngoscope. 2002;112(1):59-63.

12. Mortimore S, Wormald PJ, Oliver S. Antibiotic choice in acute and complicated sinusitis. J Laryngol Otol. 1998;112(3):264-268.

13. Harris GJ. Subperiosteal abscess of the orbit. Age as a factor in the bacteriology and response to treatment. Ophthalmology. 1994;101(3): 585-595.

14. Kabre A, Diallo O, Traore C, Cisse R. Abces intraobitaires: a propos de deux cas [Intraorbital abscess: a report of two cases]. AJSN. 2002;27(1):106-112. French.

15. Dolman PJ, Glazer LC, Harris GJ, Beatty RL, Massaro BM. Mechanisms of visual loss in severe proptosis. Ophthal Plast Reconstr Surg. 1991; 7(4):256-260.
Clinical Ophthalmology

\section{Publish your work in this journal}

Clinical Ophthalmology is an international, peer-reviewed journal covering all subspecialties within ophthalmology. Key topics include: Optometry; Visual science; Pharmacology and drug therapy in eye diseases; Basic Sciences; Primary and Secondary eye care; Patient Safety and Quality of Care Improvements. This journal is indexed on Submit your manuscript here: http://www.dovepress.com/clinical-ophthalmology-journal

\section{Dovepress}

PubMed Central and CAS, and is the official journal of The Society of Clinical Ophthalmology (SCO). The manuscript management system is completely online and includes a very quick and fair peer-review system, which is all easy to use. Visit http://www.dovepress.com/ testimonials.php to read real quotes from published authors. 